\title{
Factors associated with smoking among tuberculosis patients in Spain
}

\author{
María Ángeles Jiménez-Fuentes ${ }^{1,2,3 *}$, Teresa Rodrigo ${ }^{2,3,4,5}$, María Neus Altet ${ }^{2,3,6}$, Carlos A. Jiménez-Ruiz ${ }^{7}$, \\ Martí Casals ${ }^{2,5,8}$, Antón Penas ${ }^{2,9}$, Isabel Mir ${ }^{2,10}$, Segismundo Solano Reina ${ }^{11}$, Juan Antonio Riesco-Miranda ${ }^{12,13}$, \\ Joan A. Caylá, 2,3,4,14 and Smoking and Tuberculosis Research Working Group
}

\begin{abstract}
Background: To determine the prevalence of smoking and analyze associated factors in a cohort of patients diagnosed with tuberculosis (TB) in Spain between 2006 and 2013.

Methods: Multicenter, cross-sectional, descriptive, observational study using a national database of TB patients, using logistic regression to calculate odds ratios (OR) and confidence intervals (Cl).

Results: We analyzed 5,846 cases (62 \% men, mean age 39 years, $33 \%$ foreigners). $23.4 \%$ were alcohol abuser, $1.3 \%$ were injected drug users (IDU), $4.6 \%$ were co-infected with HIV, and $7.5 \%$ had a history of TB treatment. $6.6 \%$ and 0. $8 \%$ showed resistance to one and multiple drugs, respectively. The predominant clinical presentation was pulmonary (71 \%) with a cavitary radiological pattern in $32.8 \%$ of cases. $82 \%$ of cases were confirmed microbiologically, and $54 \%$ were smear-positive microscopy.

2,300 (39.3\%) patients were smokers. The following factors were associated with smoking: male sex (OR=2.26;Cl:1.97;2. 60), Spanish origin ( $\mathrm{OR}=2.79 ; \mathrm{Cl}: 2.40-3.24)$, alcoholism ( $\mathrm{OR}=2.85 ; \mathrm{Cl}: 2.46 ; 3.31)$, IDU (OR=2.78;Cl:1.48;5.52), homelessness $(\mathrm{OR}=1.99 ; \mathrm{Cl}: 1.14-3.57)$, pulmonary $\mathrm{TB}(\mathrm{OR}=1.61 ; \mathrm{Cl}: 1.16 ; 2.24)$, cavitary radiological pattern $(\mathrm{OR}=1.99 ; \mathrm{Cl}: 1.43 ; 2.79)$ and a smear-positive microscopy at the time of diagnosis ( $O R=1.39 ; C l: 1.14 ; 1.17)$.

Conclusions: The prevalence of smoking among TB patients is high. Smokers with TB have a distinct sociodemographic, clinical, radiological and microbiological profile to non-smokers.
\end{abstract}

Keywords: Tuberculosis, Smoking, Predictors, Prevention

\section{Background}

Smoking and tuberculosis (TB) are two of the biggest public health problems worldwide [1]. Smoking is one of the leading preventable causes of premature death, producing 6 million deaths a year. At present, about $33 \%$ of the world population smokes, mainly in countries with a high prevalence of TB. In turn, TB causes 9.6 million incident cases and 1.5 million deaths in 2014 [2, 3].

While, the relationship between smoking and TB has been recognized for almost a century, the impact of smoking on $\mathrm{TB}$ has only been demonstrated in last

\footnotetext{
* Correspondence: m.jimenez@vhebron.net

'Unidad de Tuberculosis Valle de Hebrón-Drassanes. Programa Especial de Enfermedades Infecciosas, Hospital Universitario Valle de Hebrón, Av Drassanes, 17-21, 08001 Barcelona, Spain

${ }^{2}$ Programa Integrado de Investigación en Tuberculosis (PII TB) de la Sociedad Española de Neumología y Cirugía Torácica (SEPAR), Barcelona, Spain Full list of author information is available at the end of the article
}

decade [4-7]: both active and passive exposure to smoke are independent risk factors for TB infection $[8,9]$, the progression of $\mathrm{TB}$ infection to disease [10, 11], greater disease severity, and increased risk of post-treatment relapse and mortality [12-14].

A recent study based on mathematical modelling estimated that, between 2010 and 2050, smoking could raise the number of TB cases worldwide by 18 million, and substantially increase secondary mortality if current trends in tobacco consumption are maintained [15]. The World Health Organization and the International Union Against Tuberculosis and Lung Disease issued regulations in 2007 to control these two clearly related epidemics [1].

Smoking prevalence among TB patients could be higher than the objectified general population in many countries; in China a case-control study shows 
prevalence of $54.6 \%$ [16], in South Africa found that $56 \%$ of people with active TB were smokers [17], a study in rural India found that $81.5 \%$ of TB cases had previously smoked at some time in their life [18] and in Georgia the prevalence of current smokers among the diagnoses of TB represents $45.9 \%$ [19]. Currently, there are no reliable data on the prevalence of smoking among TB patients in Spain, with the exception of one study carried out in Catalonia between 1996 and 2002, which reported a smoking prevalence of $34.9 \%$ [12].

The aim of our study was to determine the prevalence of smoking among patients diagnosed with TB in Spain between 2006 and 2013, and to identify factors associated with smoking in this population. The ultimate goal is to design assistance and support strategies for smoking cessation to improve clinical outcomes, reduce TB transmissibility, and improve prognosis and survival.

\section{Methods}

We performed a multicenter, cross-sectional, descriptive, analytical and observational study.

We included patients diagnosed with TB between 1 January 2006 and 31 December 2013 within the catchment area of the Integrated TB Research Program (PII TB) Working Group of the Spanish Society of Pneumology and Thoracic Surgery (SEPAR) in 60 centers in Spanish Autonomous Communities.

We included patients aged $>18$ years with a diagnosis of TB, as determined by: 1) positive smear, or negative smear with positive culture for Mycobacterium tuberculosis, or extra-pulmonary TB as demonstrated by granulomas tubercular on histology; 2) patients suspected TB (clinical, radiological, epidemiological and/or laboratory results) with a good response to $\mathrm{TB}$ treatment without other diagnosis.

Patients were considered to be smokers if they reported having smoked $\geq 1$ cigarettes per day continuously during the year preceding the diagnosis of TB and no smoker the person who has smoked less than 100 cigarettes in his life [20].

The information is collected by clinical researcher from the interview and review of the history in three visits: at the time of diagnosis, the second month and the end of treatment. For all cases, we collected sociodemographic data, living status, origin (native or immigrant), place of diagnosis, alcohol consumption (men consuming over $280 \mathrm{~g}$ alcohol per week, an women over $168 \mathrm{gr}$, were considered alcoholics), use of intravenous heroin or/and cocaine drugs (IDU), delayed diagnosis ( $>50$ days), TB localization, radiology, microbiology results and sensitivity study, history of TB, HIV infection, clinical progression, drug treatment, and treatment outcome (correct: cured, treatment completed; incorrect: therapeutic failure, moved away/transferred, lost to follow-up and death).

The information obtained from each patient was stored in an electronic data collection notebook (DCN) implemented in a software application available to each study investigator via a personal identifier and password.

The study was conducted according to the requirements of the Declaration of Helsinki and Spanish Data Protection Law 15/1999. All patients gave their informed consent to participate in this study, which was approved by the Clinical Research Ethics Committee of Vall d'Hebron University Hospital Foundation - Research Institute.

\section{Statistical analysis}

We performed a descriptive study of the prevalence of smoking among participants, and the frequency distribution of other variables. We performed bivariate analysis of factors potentially associated with smoking (yes/no) by comparing proportions between groups using the $\chi^{2}$ test. Results with $\mathrm{p}<0.05$ were considered statistically significant. For the multivariable analysis, we fit logistic regression models using the backward stepwise selection method to include variables that were relevant to the study, as well as those with $\mathrm{p}<0.001$ in the bivariate analysis, and to compute Odds Ratios (OR) and $95 \%$ Confidence Intervals (CI). We used the HosmerLemeshow test to evaluate the goodness of fit of each model. All analysis was performed using IBM SPSS Statistic19.

\section{Results}

We included 5,846 TB patients; with a mean age of 39 years (range 18-100 years), 3,626 (62 \%) men, and 1,941 foreigners (33\%). 23.4 \% were pathological alcohol drinkers, and $1.3 \%$ were IDU. $4.6 \%$ of cases were coinfected with HIV, 438 (7.5\%) had a history of TB treatment, and $49.5 \%$ were diagnosed by hospital emergency services. $6.6 \%$ of cases were found to be resistant to any drug, and $0.8 \%$ to multiple drugs. The predominant clinical presentation was pulmonary tuberculosis $(4,149$ cases, $71 \%$ ), with a cavitary radiological pattern in $32.8 \%$ of cases. $82 \%$ of cases were confirmed microbiologically, of which $54 \%$ were smear-positive.

A total of 2,300 (39.3\%) patients were smokers, and this proportion remained stable during the course of the study Fig. 1.

The bivariate analysis to detect factors associated with smoking (Table 1) indicated a higher prevalence of smoking among men, Spanish nationals, and individuals who live alone or in confinement, or who are homeless, regardless of age or employment status. Smoking was also associated with other harmful habits, such as 


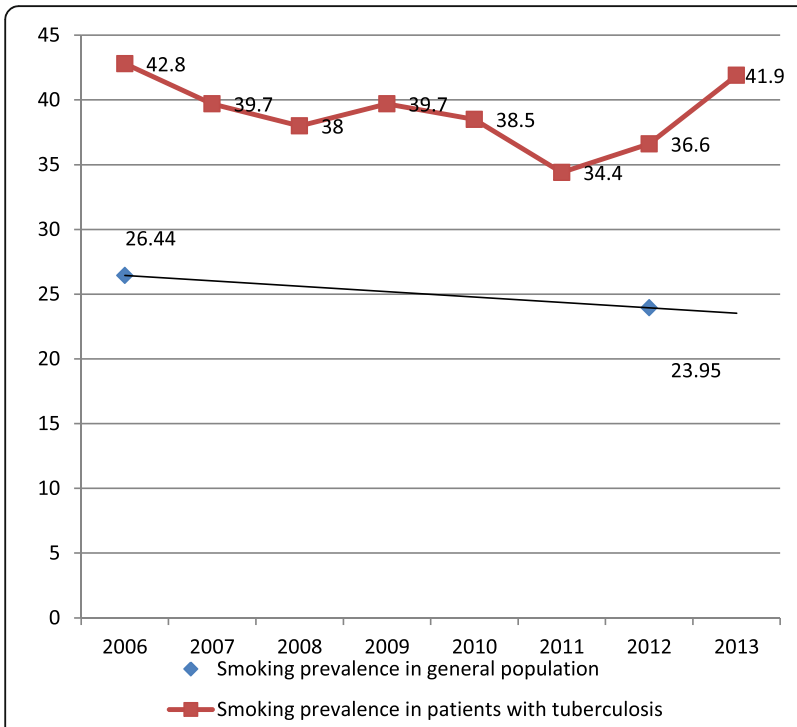

Fig. 1 Trend in the prevalence of smoking in the general population and among smokers with tuberculosis 2006-2013

alcoholism and the use of injected drugs. Smoking was more frequent in cases with coexisting HIV infection, and those with a history of TB treatment. The prevalence of delayed diagnosis was significantly higher in smokers than in non-smokers. Pulmonary forms of TB, radiological cavitation, and positive smear-test results were more common in smokers, as was therapeutic noncompliance, and the need for directly observed treatment (DOT) administration and poorer treatment outcome. In contrast, we observed no differences between smokers and non-smokers in terms of single or multi-drug resistance, prescribed treatment, or clinical or radiological progression (Table 1).

The multivariate analysis (Table 2) showed that the following factors were associated with smoking at the time of diagnosis in this cohort of TB patients: male gender $(\mathrm{OR}=2.26, \mathrm{CI} 1.97-2.60)$, being native Spanish $(\mathrm{OR}=2.79$, CI 2.40-3.24), alcohol consumption $(\mathrm{OR}=$ 2.85 , CI 2.46-3.31), IDU (OR $=2.78$, CI 1.48-5.52), poverty $(\mathrm{OR}=1.99$, CI 1.14-3.57), pulmonary forms of $\mathrm{TB}$ $(\mathrm{OR}=1.61, \mathrm{CI} 1.16-2.24)$, cavitary radiological patterns $(\mathrm{OR}=1.99, \mathrm{CI} 1.43-2.79)$ and positive smear-test results $(\mathrm{OR}=1.39$, CI 1.14-1.71).

\section{Discussion}

We observed a high prevalence of smoking among individuals diagnosed with TB in Spain between 2006 and 2013. Smoking was associated with male gender, being native Spanish, the consumption of other drugs, a precarious social position, more severe and more developed lung disease, and poorer treatment outcome than in non-smoking TB patients.
In this study, we found that $39.3 \%$ of TB patients were regular smokers at the time of diagnosis, a much higher figure than that reported for the general population in Spain, $23.95 \%$, according to data from the National Health Survey 2011-2013 and it remained well above this value, and with little annual variation (Fig. 1); this level was similar to that published for Catalonia in 2002 (34.9\%) [12]. However, during the period of this study, we observed a steady decline in smoking prevalence in Spain, $26.44 \%$ in 2006 to $23.95 \%$ in 2013 [21], as a result of legislative changes and prevention programs [22]. Thus, the TB patients smokers may be resistant to general anti-smoking measures, possibly for social reasons or because of differences in its level of addiction to nicotine. This hinders smoking cessation in this group, and highlights the need for a different set of cessation strategies to those used in the general population.

In our sample, we found that men smoke significantly more than women; $62 \%$ of men with TB were smokers, compared to $27.87 \%$ of males in the general population during the same period. In comparison, the prevalence of smoking among female TB patients (25.3\%) was only 5 percentage points higher than in the general population (20.2\%). Worldwide, TB is known to be more common in men than in women. A study conducted in 22 countries with a high burden of TB found that smoking was a predictor of increased reporting of $\mathrm{TB}$ in males [23], suggesting that the differences in disease rates between sexes could be due to the higher prevalence of smoking in men, a pattern that persists in virtually all ethnic groups and countries [2].

While a third of the cases included in this study were foreigners, the prevalence of smoking was much lower in this group $(27.5 \%)$ than in native Spanish patients (45.2\%). Previous studies carried out in Spain show that the intensity of drug and alcohol consumption is lower in the immigrant population than in natives. This pattern has been attributed to cultural differences and economic difficulties that reduce consumption, and is maintained in immigrants with TB [24].

Smoking was also associated with situations of social precariousness, and its prevalence was significantly higher among individuals who live alone, in poverty, or in confinement, regardless of their age or employment status. Smoking was also associated with pathological alcohol consumption (65.9\%) and injected drug use (82.1\%). These risk factors are classically associated with TB in people at risk of social marginalization, as previously described in our setting [12, 24, 25]. The proportion of HIV co-infection was low in this sample (4.6\%), and HIV was associated with tobacco use in the bivariate but not multivariate analysis, possibly because of the low number of co-infected cases. The clinical presentation of TB in smokers was mainly pulmonary and disseminated, 
Table 1 Characteristics of 5,846 tuberculosis patients. Factors related to smoking at the time of tuberculosis diagnosis at bivariate level

\begin{tabular}{|c|c|c|c|c|c|c|c|}
\hline & \multirow{2}{*}{$\begin{array}{l}\text { Total } \\
\text { N } 5846\end{array}$} & \multicolumn{2}{|c|}{ Non-smoker } & \multicolumn{2}{|l|}{ Smoker } & \multicolumn{2}{|c|}{ Bivariate analysis } \\
\hline & & N 3546 & $61 \%$ & N 2300 & $39 \%$ & OR (95 \% Cl) & $P$-value \\
\hline \multicolumn{8}{|l|}{ Sex } \\
\hline Women & 2082 & 1556 & 74,7 & 526 & 25,3 & Ref & \\
\hline Men & 3626 & 1911 & 52,7 & 1715 & 47,3 & $2.65(2.36 ; 2.99)$ & $<0.001$ \\
\hline Unknown & 138 & 79 & 57,2 & 59 & 42,8 & $2.21(1.55 ; 3.14)$ & $<0,001$ \\
\hline \multicolumn{8}{|l|}{ Age } \\
\hline Unknown & 138 & 118 & 85,5 & 20 & 15,5 & Ref & \\
\hline $18-30$ years & 1627 & 1077 & 66,2 & 550 & 33,8 & $2.99(1.88 ; 5.01)$ & $<0,001$ \\
\hline $31-50$ years & 2405 & 1212 & 50,4 & 1193 & 49,6 & $5.77(3.65 ; 9.61)$ & $<0,001$ \\
\hline$>50$ years & 1676 & 1139 & 68 & 537 & 32 & $2.76(1.74 ; 4.62)$ & $<0,001$ \\
\hline \multicolumn{8}{|l|}{ Origin } \\
\hline Immigrant & 1941 & 1408 & 72,5 & 533 & 27,5 & Ref & \\
\hline Native & 3905 & 2138 & 54,8 & 1767 & 45,2 & $2,18(1,94 ; 2.46)$ & $<0,001$ \\
\hline \multicolumn{8}{|l|}{ Cohabitation status } \\
\hline Group & 651 & 431 & 66,2 & 220 & 33,8 & Ref & \\
\hline Alone & 554 & 276 & 49,8 & 278 & 50,2 & $1,97(1,56 ; 2,49)$ & $<0,001$ \\
\hline Homeless & 100 & 25 & 25 & 75 & 75 & $5,84(3,65 ; 9,63)$ & $<0,001$ \\
\hline Confinement & 80 & 38 & 47,5 & 42 & 52,5 & $2,16(1,35 ; 3,47)$ & 0,001 \\
\hline With Family & 4293 & 2683 & 62,5 & 1610 & 37,5 & $1,18(0,99 ; 1,40)$ & 0,067 \\
\hline Unknown & 168 & 93 & 55,4 & 75 & 44,6 & $1,58(1,12 ; 2,23)$ & 0,01 \\
\hline \multicolumn{8}{|l|}{ Employment status } \\
\hline Retired & 978 & 792 & 81 & 186 & 19 & Ref & \\
\hline Active & 3026 & 1794 & 59,3 & 1232 & 40,7 & $2,92(2.46 ; 3,95)$ & $<0.001$ \\
\hline Unemployed & 1481 & 730 & 49,3 & 751 & 50,7 & $4,38(3,63 ; 5,30)$ & $<0.001$ \\
\hline Incapacity & 110 & 59 & 53,6 & 51 & 46,4 & $3,68(2,44 ; 5,53)$ & $<0.001$ \\
\hline Unknown & 251 & 171 & 68,1 & 80 & 31,9 & $1,99(1,46 ; 2,71)$ & $<0.001$ \\
\hline \multicolumn{8}{|l|}{ Alcohol } \\
\hline No & 4475 & 3079 & 68,8 & 1396 & 31,2 & Ref & \\
\hline Yes & 1371 & 467 & 34,1 & 904 & 65,9 & $4,27(3.76 ; 4,86)$ & $<0,001$ \\
\hline \multicolumn{8}{|l|}{ IDU } \\
\hline No & 5768 & 3532 & 61,2 & 2236 & 38,8 & Ref & \\
\hline Yes & 78 & 14 & 17,9 & 64 & 82,1 & $7,15(4.12 ; 13,4)$ & $<0,001$ \\
\hline \multicolumn{8}{|l|}{ HIV } \\
\hline No & 4547 & 2783 & 61,2 & 1764 & 38,8 & $1,10(0,96 ; 1,27)$ & 0,15 \\
\hline Yes & 269 & 108 & 40,1 & 161 & 59,9 & $2,60(1,97 ; 3,92)$ & 0,001 \\
\hline Unknown & 1030 & 655 & 63,5 & 375 & 36.4 & Ref & \\
\hline \multicolumn{8}{|l|}{ Diagnosis } \\
\hline Specialits service & 898 & 602 & 67 & 296 & 33 & Ref & \\
\hline Hospital Emergency Room & 2916 & 1691 & 58 & 1225 & 42 & $1,47(1,26 ; 1,73)$ & $<0,001$ \\
\hline Primere care & 1106 & 660 & 59,7 & 446 & 40,3 & $1,37(1,14 ; 1,65)$ & 0,001 \\
\hline Other & 754 & 494 & 65,5 & 260 & 34,5 & $1,07(0,87 ; 1,31)$ & 0,515 \\
\hline Unknown & 172 & 99 & 57,6 & 73 & 42,4 & $1,5(1,07 ; 2,09)$ & 0,018 \\
\hline
\end{tabular}


Table 1 Characteristics of 5,846 tuberculosis patients. Factors related to smoking at the time of tuberculosis diagnosis at bivariate level (Continued)

\begin{tabular}{|c|c|c|c|c|c|c|c|}
\hline \multicolumn{8}{|l|}{ Prior Treatment } \\
\hline No & 5287 & 3245 & 61,4 & 2042 & 38,6 & Ref & \\
\hline Yes & 438 & 224 & 51,1 & 214 & 48,9 & $1,52(1,25 ; 1,85)$ & $<0,001$ \\
\hline \multicolumn{8}{|l|}{ Localization } \\
\hline Extra-pulmonary & 611 & 497 & 81,3 & 114 & 18,7 & Ref & \\
\hline Pulmonary & 4149 & 2299 & 55,4 & 1850 & 44,6 & $3,50(2.84 ; 4.35)$ & $<0,001$ \\
\hline Disseminated & 301 & 198 & 65,8 & 103 & 34,2 & $2,27(1,66 ; 3,10)$ & $<0,001$ \\
\hline Unknown & 785 & 552 & 70,3 & 233 & 29,7 & $1,84(1,43 ; 2,38)$ & $<0,001$ \\
\hline \multicolumn{8}{|l|}{ Radiology } \\
\hline Normal & 610 & 480 & 78,7 & 130 & 21,3 & Ref & \\
\hline Abnormal cavitary & 1922 & 889 & 46,3 & 1033 & 53,7 & $4,28(3.47 ; 5,32)$ & $<0,001$ \\
\hline Abnormal non cavitary & 3114 & 2042 & 65,6 & 1072 & 33,4 & $1,94(1,58 ; 2,39)$ & $<0,001$ \\
\hline Unknown & 200 & 135 & 67,5 & 65 & 32,5 & $1,78(1,24 ; 2,53)$ & 0,002 \\
\hline \multicolumn{8}{|l|}{ Microbiology } \\
\hline Culture $(-)$ & 1055 & 779 & 73,8 & 276 & 26,2 & Ref & \\
\hline Microscopy smear (+) & 3144 & 1636 & 52 & 1508 & 48 & $2,60(2,23 ; 3,04)$ & $<0,001$ \\
\hline Microscopy smear $(+)$, culture $(-)$ & 1647 & 1131 & 68,7 & 516 & 31,3 & $1,29(1,08 ; 1,53)$ & 0,004 \\
\hline \multicolumn{8}{|l|}{ Single-drug resistance } \\
\hline No & 5458 & 3311 & 60,7 & 2147 & 39,3 & Ref & \\
\hline Yes & 388 & 235 & 60,6 & 153 & 39,4 & $1,00(0,81 ; 1,24)$ & 0,968 \\
\hline \multicolumn{8}{|l|}{ Multi-drug resistance } \\
\hline No & 5797 & 3517 & 60,7 & 2280 & 39,3 & Ref & \\
\hline Yes & 49 & 29 & 59,2 & 20 & 40,8 & $1,07(0,59 ; 1,88)$ & 0,827 \\
\hline \multicolumn{8}{|l|}{ Delayed diagnosis } \\
\hline Unknown & 343 & 226 & 65,9 & 117 & 34,1 & Ref & \\
\hline$<50$ days & 2777 & 1680 & 60,5 & 1097 & 39,5 & $1,26(1,00 ; 1,60)$ & 0,052 \\
\hline$>50$ days & 2726 & 1640 & 60,2 & 1086 & 39,8 & $1,28(1,01 ; 1,62)$ & 0,04 \\
\hline \multicolumn{8}{|l|}{ Treatment indicated } \\
\hline Unknown & 197 & 132 & 67 & 65 & 33 & Ref & \\
\hline 3 drugs & 2566 & 1521 & 59,3 & 1045 & 40,7 & $1,39(1,03 ; 1,91)$ & 0,032 \\
\hline 4 drugs & 2819 & 1732 & 61,4 & 1087 & 38,6 & $1,27(0,94 ; 1,74)$ & 0,119 \\
\hline Others & 264 & 161 & 61 & 103 & 39 & $1,30(0,88 ; 1,92)$ & 0,186 \\
\hline \multicolumn{8}{|l|}{ Need for DOT } \\
\hline Unknown & 597 & 373 & 62,5 & 224 & 37,5 & Ref & \\
\hline No & 4629 & 2834 & 61,2 & 1795 & 38,8 & $1,05(0,89 ; 1,26)$ & 0,555 \\
\hline Yes & 620 & 339 & 54,7 & 281 & 45,3 & $1,38(1,10 ; 1,74)$ & 0,006 \\
\hline \multicolumn{8}{|l|}{ Clinical progression } \\
\hline Unknown & 569 & 354 & 62,2 & 215 & 37,8 & Ref & \\
\hline Improved & 4860 & 2936 & 60,4 & 1924 & 39,6 & $1,08(0,90 ; 1,19)$ & 0,406 \\
\hline Stable & 368 & 226 & 61,4 & 142 & 38,6 & $1,03(0,79 ; 1,35)$ & 0,805 \\
\hline Progressed & 49 & 30 & 61,2 & 19 & 38,8 & $1,05(0,56 ; 1,89)$ & 0,884 \\
\hline \multicolumn{8}{|l|}{ Radiological progression } \\
\hline Stable & 981 & 626 & 63,8 & 355 & 36,2 & Ref & \\
\hline Improved & 3750 & 2238 & 59,7 & 1512 & 40,3 & $1,19(1,03 ; 1,38)$ & 0,018 \\
\hline
\end{tabular}


Table 1 Characteristics of 5,846 tuberculosis patients. Factors related to smoking at the time of tuberculosis diagnosis at bivariate level (Continued)

\begin{tabular}{|c|c|c|c|c|c|c|c|}
\hline Progressed & 36 & 17 & 47,2 & 19 & 52,8 & $1,97(1,00 ; 3,89)$ & 0,049 \\
\hline Unknown & 1079 & 665 & 61,6 & 414 & 38,4 & $1,10(0,92 ; 1,31)$ & 0,307 \\
\hline \multicolumn{8}{|c|}{ Treatment outcome } \\
\hline Unknown & 520 & 324 & 62,3 & 196 & 37,7 & Ref & \\
\hline Correct & 5079 & 3123 & 61,5 & 1956 & 38,5 & $1,04(0,86 ; 1,25)$ & 0,717 \\
\hline Incorrect & 247 & 99 & 40,1 & 148 & 59,9 & $2,47(1,81 ; 3,37)$ & $<0,001$ \\
\hline
\end{tabular}

OR odds ratio

Cl confidence interval

IDU injecten drug users

$H V I$ humanimmunodeficiency virus

while isolated extra-pulmonary TB was rare in smokers. Radiologically, we also observed more extensive lesions in these patients, with more frequent cavitation and positive smear results at the time of diagnosis. These findings are similar to those reported by other authors, mentioned above, and reflect generally more serious and advanced disease [12, 13]. Several studies in animal models and humans have shown that exposure to tobacco smoke causes immunological changes, acting on alveolar macrophages by decreasing the production of TNF- $\alpha$, IFN- $\gamma$, and mucociliary clearance, promoting disease progression [26-28], delaying sputum conversion and thereby extending the period of transmissibility [29]. In this sense, and in contrast to other studies [12], the observed delay in diagnosis was also higher in smokers, possibly because cough is a common symptom in these patients, and it may be difficult to perceive changes that alert the subject and motivate them to seek medical advice.

We did not find any significant differences between smokers and non-smokers in the presence of single or multi-drug resistance, or in the treatment initially indicated, although directly observed therapy was indicated more frequently in smokers than in non-smokers. Poorer treatment outcome was also more common among smokers. Therefore, smokers require closer monitoring and greater resources to ensure therapeutic compliance and the ultimate success of treatment, leading to increased healthcare spending. Other studies have also found a greater need for hospitalization, longer stays [12], and increased risk of relapse following treatment. A study in Taiwan found that people who smoke more than 10 cigarettes per day have twice the risk of relapse of non-smokers after proper treatment [14]. In our series, $7.5 \%$ of patients had a history of previous illness, which was significantly with smoking.

Our study has some limitations. Our work can only show association between smoking and tuberculosis from an epidemiological point of view, and cannot show causality.
We did not quantify daily tobacco consumption, the number of years of smoking, type of tobacco used, or the intensity of passive smoking, which prevents us from evaluating a possible dose-response relationship. Only smoking status at the time of diagnosis was recorded, and we cannot determine if this persisted throughout the patient's follow-up. Thus, it was not possible to assess the impact of smoking cessation on disease progression or the treatment outcome.

We could not collect systematic information on smoking cessation interventions by health professionals, since this survey depended solely on routine clinical practice and the experience of the individual medical teams in each of the participating centers. Some centers gave brief anti-smoking counseling, along with basic health education during each visit. This type of intervention has previously proven useful and feasible in other TB treatment programs [30], but is not included in local or national recommendations or regulations in our setting. The introduction of drug therapy for smoking cessation in patients with TB is still a pending task, given the limited clinical experience available [31]; few professionals feel prepared to advise their TB patients on smoking cessation [32], and cessation drugs are not widely accessible due to their high price because Spain are not subsidized by the National Health System and makes it impossible the access groups with economic difficulties as they are often patients with TB.

One of this study's strong points is the large number of cases recruited representing $12 \%$ of total cases reported in the regions that are part of the Spanish state during the study period [33] and the quality of the information, which allowed us to analyze trends in prevalence during the study period and to evaluate factors associated with smoking among TB patients.

\section{Conclusion}

The prevalence of smoking among TB patients in Spain is high. Smokers with TB have a distinct sociodemographic, 
Table 2 Characteristics of 5,846 tuberculosis patients. Factors related to smoking at the time of tuberculosis diagnosis at multivariate level

\begin{tabular}{|c|c|c|c|c|c|c|c|}
\hline & \multirow{2}{*}{$\begin{array}{l}\text { Total } \\
\text { N } 5846\end{array}$} & \multicolumn{2}{|c|}{ Non-smoker } & \multicolumn{2}{|l|}{ Smoker } & \multicolumn{2}{|c|}{ Multi-variate analysis. } \\
\hline & & N 3546 & $61 \%$ & N 2300 & $39 \%$ & OR $(95 \% \mathrm{Cl})$ & $P$-value \\
\hline \multicolumn{8}{|l|}{ Sex } \\
\hline Women & 2082 & 1556 & 74,7 & 526 & 25,3 & Ref & \\
\hline Men & 3626 & 1911 & 52,7 & 1715 & 47,3 & $2.26(1.97 ; 2.60)$ & $<0.001$ \\
\hline Unknown & 138 & 79 & 57,2 & 59 & 42,8 & $2.19(1.46 ; 3.28)$ & $<0.001$ \\
\hline \multicolumn{8}{|l|}{ Age } \\
\hline Unknown & 138 & 118 & 85,5 & 20 & 15,5 & Ref & \\
\hline $18-30$ years & 1627 & 1077 & 66,2 & 550 & 33,8 & $2.39(1.44 ; 4,13)$ & $<0.001$ \\
\hline $31-50$ years & 2405 & 1212 & 50,4 & 1193 & 49,6 & $3.45(2.09 ; 5,94$ & $<0.001$ \\
\hline$>50$ years & 1676 & 1139 & 68 & 537 & 32 & $2.52(1.50 ; 4.42$ & $<0.001$ \\
\hline \multicolumn{8}{|l|}{ Origin } \\
\hline Immigrant & 1941 & 1408 & 72,5 & 533 & 27,5 & Ref & \\
\hline Native & 3905 & 2138 & 54,8 & 1767 & 45,2 & $2,79(2,40 ; 3,24)$ & $<0,001$ \\
\hline \multicolumn{8}{|l|}{ Cohabitation status } \\
\hline Group & 651 & 431 & 66,2 & 220 & 33,8 & Ref & \\
\hline Alone & 554 & 276 & 49,8 & 278 & 50,2 & $1,21(0,91 ; 1,60)$ & 0,174 \\
\hline Homeless & 100 & 25 & 25 & 75 & 75 & $1,99(1,14 ; 3,57)$ & $<0.001$ \\
\hline Confinement & 80 & 38 & 47,5 & 42 & 52,5 & $1,70(0,98 ; 2,97)$ & 0,056 \\
\hline With Family & 4293 & 2683 & 62,5 & 1610 & 37,5 & $0,89(0,72 ; 1,11)$ & 0,317 \\
\hline Unknown & 168 & 93 & 55,4 & 75 & 44,6 & $1,35(0,89 ; 2,04)$ & 0,147 \\
\hline \multicolumn{8}{|l|}{ Alcohol } \\
\hline No & 4475 & 3079 & 68,8 & 1396 & 31,2 & Ref & \\
\hline Yes & 1371 & 467 & 34,1 & 904 & 65,9 & $2,85(2,46 ; 3,31)$ & $<0,001$ \\
\hline \multicolumn{8}{|l|}{ IDU } \\
\hline No & 5768 & 3532 & 61,2 & 2236 & 38,8 & & \\
\hline Yes & 78 & 14 & 17,9 & 64 & 82,1 & $2.78(1.48 ; 5.52)$ & $<0,001$ \\
\hline \multicolumn{8}{|l|}{ HIV } \\
\hline No & 4547 & 2783 & 61,2 & 1764 & 38,8 & $0,81(0,34 ; 2,07)$ & 0,646 \\
\hline Yes & 269 & 108 & 40,1 & 161 & 59,9 & $1,48(0,59 ; 3,94)$ & 0,412 \\
\hline Unknown & 1030 & 655 & 63,5 & 375 & 36.4 & Ref & \\
\hline \multicolumn{8}{|l|}{ Prior Treatment } \\
\hline No & 5287 & 3245 & 61,4 & 2042 & 38,6 & Ref & \\
\hline Yes & 438 & 224 & 51,1 & 214 & 48,9 & $1,12(0,89 ; 2,04)$ & 0,314 \\
\hline \multicolumn{8}{|l|}{ Localization } \\
\hline Extra-pulmonary & 611 & 497 & 81,3 & 114 & 18,7 & Ref & \\
\hline Pulmonary & 4149 & 2299 & 55,4 & 1850 & 44,6 & $1,61(1,16 ; 2,24)$ & $<0,001$ \\
\hline Disseminated & 301 & 198 & 65,8 & 103 & 34,2 & $1,12(0,73 ; 1,70)$ & 0,59 \\
\hline Unknown & 785 & 552 & 70,3 & 233 & 29,7 & $1,14(0,80 ; 1,63)$ & 0,458 \\
\hline \multicolumn{8}{|l|}{ Radiology } \\
\hline Normal & 610 & 480 & 78,7 & 130 & 21,3 & Ref & \\
\hline Abnormall cavitary & 1922 & 889 & 46,3 & 1033 & 53,7 & $1,99(1,43 ; 2,79)$ & $<0,001$ \\
\hline Abnormal non cavitary & 3114 & 2042 & 65,6 & 1072 & 33,4 & $1,24(0,91 ; 1,70)$ & 0,167 \\
\hline Unknown & 200 & 135 & 67,5 & 65 & 32,5 & $1,21(0,77 ; 1,89)$ & 0,4 \\
\hline
\end{tabular}


Table 2 Characteristics of 5,846 tuberculosis patients. Factors related to smoking at the time of tuberculosis diagnosis at multivariate level (Continued)

\begin{tabular}{|c|c|c|c|c|c|c|c|}
\hline \\
\hline \multicolumn{8}{|l|}{$\begin{array}{l}\text { Microbiology } \\
\text { Culture (-) }\end{array}$} \\
\hline Microscopy smear (+) & 3144 & 1636 & 52 & 1508 & 48 & $1,39(1,14 ; 1,71)$ & $<0,001$ \\
\hline Microscopy smear $(+)$, culture $(-)$ & 1647 & 1131 & 68,7 & 516 & 31,3 & $1,01(0,82 ; 1,24)$ & 0,896 \\
\hline
\end{tabular}

OR odds ratio

$\mathrm{Cl}$ confidence interval

IDU injecten drug users

$H V I$ humanimmunodeficiency virus

clinical, radiological and microbiological profile to nonsmokers. A detailed understanding of the prevalence of smoking in our setting, as well as sociodemographic, clinical and developmental factors associated with smoking among TB patients is the first step towards designing effective strategies for control and monitoring, with the aim of improving the care of these patients, their clinical progression, and the treatment outcome.

\section{Smoking and tuberculosis research working group}

R. Agüero (H Marqués de Valdecilla, Santander); J.L. Alcázar (Instituto Nacional de Silicosis, Oviedo); N. Altet (Hospital Universitari Vall d'Hebrón Barcelona); L. Altube (H Galdakao, Galdakao); F. Álvarez Navascués (H San Agustín, Avilés, Asturias); L. Anibarro (Unidad de Tuberculosis de Pontevedra, Vigo); M. Barrón (H San Millán-San Pedro, Logroño); P. Bermúdez (Hospital Universitario Carlos Haya, Málaga), R. Blanquer (H. Dr. Peset, Valencia); L. Borderías (H San Jorge, Huesca); A. Bustamante (H Sierrallana, Torrelavega); J.L. Calpe (H La Marina Baixa, Villajoyosa); J.A. Caminero (Complejo Hospitalario Dr. Negrín, Las Palmas de Gran Canaria); F. Cañas (H. Insular de Gran Canaria, Las Palmas de Gran Canaria); F. Casas (Hospital Clínico San Cecilio, Granada), X. Casas (Hospital de Sant Boi, Llobregat), E. Cases (H Universitario La Fe, Valencia); R. Castrodeza (H El Bierzo Ponferrada-León, Ponferrada); J.J. Cebrián (H Costa del Sol, Marbella); J. E. Ciruelos (Hospital de Cruces, Guetxo); A.E. Delgado (Hospital Santa Ana, Motril), M.L. De Souza (Hospital Universitari Vall d’Hebrón. Barcelona); D. Díaz (Complejo Hospitalario Juan Canalejo, La Coruña); M Dominguez Alvarez (Hospital del Mar, Barcelona); B. Fernández (H de Navarra, Pamplona); A. Fernández (H Río Carrión, Palencia); J. Gallardo (H Universitario de Guadalajara, Guadalajara); M. Gallego (Corporación Sanitaria Parc Taulí, Sabadell); M.M. García Clemente (Hospital Central de Asturias, Oviedo), C. García (H General Isla Fuerteventura, Puerto del Rosario); FJ. García (H Universitario de la Princesa, Madrid); F.J. Garros (Hospital Santa Marina, Bilbao), A. Guerediaga (Hospital Santa Marina, Bilbao), J.A. Gullón (H San Agustín, Avilés, Asturias); C. Hidalgo (Hospital Universitario Virgen de las Nieves, Granada), M. Iglesias (H Marqués de Valdecilla, Santander); G. Jiménez (Hospital de Jaén), M.A. Jiménez-Fuentes (Hospital Universitari Vall d'Hebrón, Barcelona); J.M. Kindelan (H Universitario Reina Sofía, Córdoba); J. Laparra (H Donostia-San Sebastián, San Sebastián); R. Lera (H. Dr. Peset, Valencia); T. Lloret (H General Universitario de Valencia, Valencia); M. Marín (H General de Castellón, Castellón); J.T. Martínez (H Mutua de Terrasa, Tarrasa); E. Martínez (H de Sagunto, Sagunto); A. Martínez (H de La Marina Baixa, Villajoyosa); J.F. Medina (H Universitario Virgen del Rocío, Sevilla); C. Melero (H 12 de Octubre, Madrid); C. Milà (Hospital Universitari Vall d'Hebrón, Barcelona); I. Mir (H Son Llatzer, Palma de Mallorca): C. Morales (Hospital Universitario Virgen de las Nieves, Granada), M.A. Morales (Hospital Cruz Roja Inglesa, Ceuta); V. Moreno (H Carlos III, Madrid); A. Muñoz (Hospital Universitario Carlos Haya, Málaga), L. Muñoz (H Reina Sofía, Córdoba); C. Muñoz (H Clínico Universitario de Valencia, Valencia); J.A. Muñoz (H Universitario Central, Oviedo); I. Parra (H Universitario Virgen de la Arrixaca, El Palmar); A. Penas (Complejo Hospitalario Xeral-Calde, Lugo); J.A. Pérez (H Arnau de Vilanova, Valencia); P. Rivas (H Virgen Blanca, León); J. Rodríguez (Hospital Universitario Virgen de las Nieves, Granada), J. Ruiz-Manzano (H. Universitario Germans Trías i Pujol, Badalona); J. Sala (H Universitario Joan XXIII, Tarragona); M. Sánchez (Unidad Tuberculosis Distrito Poniente, Almería); P. Sánchez (H del Mar, Barcelona); F. Sanz (H. General Universitario de Valencia, Valencia); M. Somoza (Consorcio Sanitario de Tarrasa, Barcelona),
E. Trujillo (Complejo Hospitalario de Ávila, Ávila); E. Valencia (H Carlos III, Madrid); A. Vargas (H Universitario Puerto Real, Cádiz); I. Vidal (Complejo Hospitalario Juan Canalejo, La Coruña); R. Vidal (H. VallD'Hebrón, Barcelona); M.A. Villanueva (Hospital San Agustín, Avilés, Asturias); A. Villar (H. VallD'Hebrón, Barcelona); M. Vizcaya (Complejo Hospitalario Universitario de Albacete, Albacete); M. Zabaleta (H de Laredo, Laredo); G. Zubillaga (H Donostia-San Sebastián, San Sebastián).

\section{Funding}

This work was made possible by a grant from the Spanish Society of Pneumology and Thoracic Surgery, SEPAR 2011.

\section{Availability of data and materials}

The dataset supporting the conclusions of this article is available by request to Integrated TB Research Program (PII TB) Working Group of the Spanish Society of Pneumology and Thoracic Surgery (PII_TB_Teresa_Rodrigo@separ.es).

\section{Authors' contributions}

MJF conceived of the study, and participated in its design and coordination, acquisition of data, interpreted data analysis and drafted the manuscript. TR, MNA, CJR, AP, IM, SSR, JRM, JAC and The Smoking and Tuberculosis Research Working Group in Spain participated in the acquisition of data and have been involved in revising the manuscript. MC participated in the design of the study and performed the statistical analysis. JAC and TR participated in its design and coordination, interpreted data analysis and helped to draft the manuscript. All authors read and approved the final manuscript.

\section{Competing interests}

The authors declare that they have no competing interests.

\section{Consent for publication}

Not applicable.

\section{Ethics approval and consent to participate}

Approved by the Clinical Research Ethics Committee of Vall d'Hebron University Hospital Foundation - Research Institute. All patients gave their informed consent to participate in this study.

\section{Author details}

'Unidad de Tuberculosis Valle de Hebrón-Drassanes. Programa Especial de Enfermedades Infecciosas, Hospital Universitario Valle de Hebrón, Av Drassanes, 17-21, 08001 Barcelona, Spain. ${ }^{2}$ Programa Integrado de Investigación en Tuberculosis (PII TB) de la Sociedad Española de Neumología y Cirugía Torácica (SEPAR), Barcelona, Spain. ${ }^{3}$ Unidad de Investigación de Tuberculosis de Barcelona, Barcelona, Spain. ${ }^{4}$ Fundación Respira de la SEPAR, Barcelona, Spain. ${ }^{5}$ Centro de Investigación Biomédica en Red de Epidemiología y Salud Pública (CIBERESP), Madrid, Spain. ${ }^{6}$ Serveis Clínics S.A., Barcelona, Spain. ${ }^{7}$ Unidad Especializada de Tabaquismo de la Comunidad de Madrid, Madrid, Spain. ${ }^{8}$ Servicio de Epidemiología de la Agencia de Salud Pública de Barcelona, Barcelona, Spain. ${ }^{9}$ Hospital Lucus Augusti, Lugo, Spain. ${ }^{10}$ Hospital Son Llàtzer, Palma de Mallorca, Spain. ${ }^{11}$ Hospital Gregorio Marañón, Madrid, Spain. ${ }^{12}$ Complejo Hospitalario de Cáceres, Cáceres, Spain. ${ }^{13}$ Centro de Investigación Biomédica en Red de Enfermedades Respiratorias (CIBERES), Madrid, Spain. ${ }^{14}$ Departamento de Salud Pública, Universitat Autónoma de Barcelona, Barcelona, Spain. 
Received: 12 January 2016 Accepted: 8 September 2016 Published online: 14 September 2016

\section{References}

1. WHO, IUATLD: A WHO/The Union monograph on TB and tobacco control: joining efforts to control two related global epidemics. WHO/HTM/TB/2007.390.

2. WHO report on the global tobacco epidemic 2013. Available: http://www. who.int/tobacco/global_report/2013/en/. Accessed 11 Sep 2016.

3. World Health Organization. Global Tuberculosis report 2015. Available: http://apps.who.int/iris/bitstream/10665/191102/1/9789241565059_eng.pdf. Accessed 11 Sep 2016.

4. Bates MN, Khalakdina A, Pai M, et al. Risk of Tuberculosis from Exposure to tobacco Smoke. A systematic review and meta-analysis. Arch Intern Med. 2007;167:335-42. doi:10.1001/archinte.167.4.335.

5. Slama K, Chiang CY, Enarson DA, et al. Tobacco and tuberculosis: a qualitative systematic review and meta-analysis. Int J Tuberc Lung Dis. 2007;11:1049-61.

6. Lin H, Ezzati M, Murray M. Tobacco smoke, indoor air pollution and tuberculosis: a systematic review and meta-analysis. PLoS Med. 2007;4:e20. doi:10.1371/journal.pmed.0040020.

7. Van Ayl Smit RN, Pai M, Yew WW, et al. Global lung health: the colliding epidemics of tuberculosis, tobacco smoking, HIV and COPD. Eur Respir J. 2010:35:27-33. doi:10.1183/09031936.00072909.

8. Lindsay R, Shin S, Garfein R, et al. The association between active and passive smoking and latent tuberculosis infection in adults and children in the United States: Results from NHANES. PLoS One. 2014;9(3), e93137. doi:10.1371/journal.pone.0093137.

9. Godoy P, Caylà JA, Carmona G, Camps N, et al. Smoking in tuberculosis patients increases the risk of infection in their contacts. Int J Tuberc Lung Dis. 2013;17:771-6. Available: http://dx.doi.org/10.5588/ijtld.12.0696.

10. Alcaide J, Altet MN, Plans $P$, et al. Cigarette smoking as a risk factor for tuberculosis in young adults: A casecontrol study. Tuber Lung Dis. 1996;77(2):112-6. PMID: 8762844

11. Altet MN, Alcaide J, Plans $P$, et al. Passive smoking and risk of pulmonary tuberculosis in children immediately following infection. A case-control study. Tuber Lung Dis. 1996;77(6):537-44. doi:10.1016/S0962-8479(96)90052-0. PMID: 9039447.

12. Altet-Gómez MN, Alcaide J, Godoy P, et al. Clinical and epidemiological aspects of smoking and tuberculosis: a study of 13038 cases. Int J Tuberc Lung Dis. 2005:9(4):430-6.

13. Leung C, Wing W, Chan C, et al. Smoking adversely affects treatment response, outcome and relapse in tuberculosis. Eur Respir J. 2015;45:738-45. doi:10.1183/09031936.00114214.

14. Yen YF, Yen MY, Lin YS, et al. Smoking increases risk of recurrence after successful antituberculosis treatment: a population-based study. Int J Tuberc Lung Dis. 2014;14(4):492-8. doi:10.5588/ijtld.13.0694.

15. Basu S, Stuckler D, Bitton A, et al. Projected effects of tobacco smoking on worldwide tuberculosis control: mathematical modelling analysis. BMJ. 2011;343:D5506. Available: http://www.bmj.com/content/343/bmj.d5506.

16. Wang J, Shen $\mathrm{H}$. Review of cigarette smoking and tuberculosis in China: intervention in needed for smoking cessation among tuberculosis patients. BMC Public Health. 2009;9:292. doi:10.1186/1471-2458-9-292.

17. Brunet $L$, Pai $M$, Davids $V$, et al. High prevalence of smoking among patients with suspected tuberculosis in South Africa. Eur Respir J. 2011;38(1):139-46. doi:10.1183/09031936.00137710.

18. Gajalakshmi V, Peto R. Smoking, drinking and incident tuberculosis in rural India: population-based case-control study. Int J Epidemiol. 2009;38: 1018-145. doi:10.1093/ije/dyp225.

19. Gegia M, Magee M, Kempker R, et al. Tobacco smoking and tuberculosis treatment outcomes: a prospective cohort study in Georgia. Bull World Health Organ. 2015;93(6):390-9. doi:10.2471/BLT.14.147439.

20. Jiménez-Ruiz CA, Granda Orive Jl, Solano Reina S, et al. Treatment of smoking (2003). Arch Bronconeumol. 2003;39:514-23.

21. Instituto Nacional de Estadística. Encuesta Nacional de Salud 2006 y 2011-2013. Available: http://www.ine.es/prensa/np770.pdf. Accessed 11 Sep 2016.

22. BOE. Ley $7 / 2010$ de 30 de diciembre, por la que se modifica la Ley $28 / 2005$, de 26 de diciembre, de medidas sanitarias frente al tabaquismo y reguladora de la venta, el suministro, el consumo y la publicidad de los productos del tabaco. Available: https://www.boe.es/buscar/doc.php?id= BOE-A-2010-20138. Accessed 14 October 2015.

23. Watkins RE, PLant AJ. Does smoking explain sex differences in the global tuberculosis epidemic? Epidemiol Infect. 2006;134:333-9. doi:10.1017/ S0950268805005042

24. García-García JM, Blanquer R, Rodrigo T, et al. Social, clinical and microbiological differential characteristics of tuberculosis among immigrants in Spain. PLoS One. 2011;6:e16272. doi:10.1371/journal.pone.0051133. Published: November 30, 2012.

25. Jiménez-Fuentes MA, Augé CM, Gómez MN, et al. Screening for active tuberculosis in high-risk groups. Int J Tuberc Lung Dis. 2014;18(12):1459-65. doi:10.5588/ijtld.14.0271.

26. Feng $Y$, Kong $Y$, Barnes PF, et al. Exposure to cigarette smoke inhibits the pulmonary T-cell response to influenza virus and Mycobacterium tuberculosis. Infect Immun. 2011:79(1):229-37. doi:10.1128/IAl.00709-10.

27. Shaler CR, Horvath CN, McCormick S, et al. Continuous and discontinuous cigarette smoke exposure differentially affects protective Th1 immunity against pulmonary tuberculosis. PLoS One. 2013;8(3), e59185. doi:10.1371/ journal.pone.0059185.

28. O'Leary SM, Coleman MM, Chew WM, et al. Cigarette smoking impairs human pulmonary immunity to mycobacterium tuberculosis. Am J Respir Crit Care Med. 2014;190(12):1430-6. doi:10.1164/rccm.201407-13850C

29. de Nijenbandring Boer R, e Oliveira Souza Filho JB, Cobelens F, et al. Delayed culture conversion due to cigarette smoking in active pulmonary tuberculosis patients. Tuberculosis (Edinb). 2014;94(1):87-91. doi:10.1016/j. tube.2013.10.005.Epub20130ct31.

30. Awaisu A, Mohamad Haniki Nik M, Noorliza Mohamad N, et al. The SCIDOTS Project: Evidence of benefits of an integrated tobacco cessation intervention in tuberculosis care on treatment outcomes. Subst Abuse Treat Prev Policy. 2011;6:26. doi:10.1186/1747-597X-6-26.

31. Siddiqi K, Khan A, Ahmad M, et al. Action to stop smoking in suspected tuberculosis (ASSIST) in Pakistan: a cluster randomized, controlled trial. Ann Intern Med. 2013;158(9):667-75. doi:10.7326/0003-4819-158-9201305070-00006

32. Jiménez-Ruiz CA, Andreas S, Lewis KE, et al. Statement on smoking cessation in COPD and other pulmonary diseases and in smokers with comorbidities who find it difficult to quit. Eur Respir J. 2015. doi:10.1183/ 09031936.00092614

33. Instituto de Salud Carlos III. Available: http://www.isciii.es/ISCIII/es/ contenidos/fd-servicios-cientifico-tecnicos/fd-vigilancias-alertas/fdenfermedades/enfermedades-declaracion-obligatoria-series-temporales. shtml. Accessed 14 October 2015.

\section{Submit your next manuscript to BioMed Central and we will help you at every step:}

- We accept pre-submission inquiries

- Our selector tool helps you to find the most relevant journal

- We provide round the clock customer support

- Convenient online submission

- Thorough peer review

- Inclusion in PubMed and all major indexing services

- Maximum visibility for your research

Submit your manuscript at www.biomedcentral.com/submit 